\title{
Trophic Factor-Induced Plasticity of Synaptic Connections Between Identified Lymnaea Neurons
}

\author{
Melanie A. Woodin, ${ }^{1,3}$ Toshiro Hamakawa, ${ }^{2,3}$ Mayumi Takasaki, ${ }^{2}$ \\ Ken Lukowiak, ${ }^{1}$ and Naweed I. Syed ${ }^{1,4}$ \\ ${ }^{1}$ Respiratory and Neuroscience Research Groups \\ Faculty of Medicine \\ University of Calgary \\ Calgary, Alberta T2N 4N1, Canada \\ ${ }^{2}$ Department of Anesthesiology \\ Miyazaki Medical College \\ Kiyotake, Miyazaki, 889-1692, Japan
}

\begin{abstract}
Neurotrophic factors participate in both developmental and adult synaptic plasticity; however, the underlying mechanisms remain unknown. Using soma-soma synapses between the identified Lymnaea neurons, we demonstrate that the brain conditioned medium (CM)-derived trophic factors are required for the formation of excitatory but not the inhibitory synapse. Specifically, identified presynaptic [right pedal dorsal 1 (RPeD1) and visceral dorsal 4 (VD4)] and postsynaptic [visceral dorsal $2 / 3$ (VD2/3) and left pedal dorsal 1 (LPeD1)] neurons were soma-soma paired either in the absence or presence of CM. We show that in defined medium (DM-does not contain extrinsic trophic factors), appropriate excitatory synapses failed to develop between RPeD1 and VD2/3. Instead, inappropriate inhibitory synapses formed between VD2/3 and RPeD1. Similarly, mutual inhibitory synapses developed between VD4 and LPeD1 in DM. These inhibitory synapses were termed novel because they do not exist in the intact brain. To test whether DM-induced, inappropriate inhibitory synapses could be corrected by the addition of CM, cells were first paired in
\end{abstract}

\footnotetext{
${ }^{3}$ These authors contributed equally to this study. ${ }^{4}$ Corresponding author.
}

DM for an initial period of $12 \mathrm{hr}$. DM was then replaced with $\mathrm{CM}$, and simultaneous intracellular recordings were made from paired cells after 6-12 hr of CM substitution. Not only did CM induce the formation of appropriate excitatory synapses between both cell pairs, but it also reduced the incidence of inappropriate inhibitory synapse formation. The $\mathrm{CM}$-induced plasticity of synaptic connections involved new protein synthesis and transcription and was mediated via receptor tyrosine kinases. Taken together, our data provide the first direct insight into the cellular mechanism underlying trophic factor-induced specificity and plasticity of synaptic connections between soma-soma paired Lymnaea neurons.

\section{Introduction}

In addition to their well-defined developmental roles in cell proliferation, survival, and neurite outgrowth, neurotrophic factors have recently been shown to regulate many aspects of developmental and adult synaptic plasticity (Thoenen 1995; Schuman 1997; McAllister et al. 1999). For example, both brain-derived neurotrophic factor (BDNF) and neurotrophin-3 (NT-3) rapidly enhance synaptic transmission at the developing neuromuscular junction (NMJ) in cell culture (Lohof et al. 1993). In addition, NT-3 exerts long-term effects on the maturation of the NMJ (Wang et al. 1995; Liou et al. 1997). Likewise, both acute and long-

LEARNING \& MEMORY 6:307-316 @ 1999 by Cold Spring Harbor Laboratory Press ISSN1072-0502/99 \$5.00

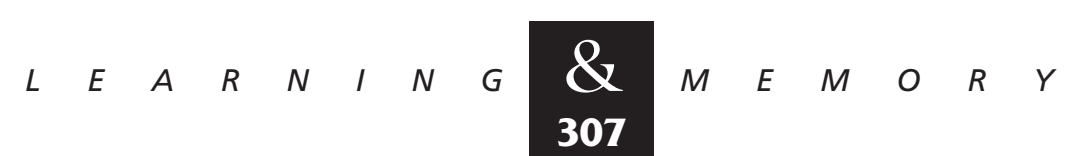


term effects of neurotrophins on synaptic transmission have also been reported in the CNS, where they modulate synaptic transmission between cultured cortical and hippocampal neurons (Kim et al. 1994; Lessmann et al. 1994; Levine et al. 1995; Li et al. 1998) and hippocampal slices (Kang and Schuman 1995; Tanaka et al. 1997). Specifically, BDNF was not only shown to potentiate glutamatergic synaptic transmission between cultured hippocampal neurons (Li et al. 1998), but it also promoted both excitatory and inhibitory synapse formation between these neurons (Vicario-Abejón et al. 1998). NT-3, on the other hand, induced the formation of excitatory synapses only (Vicario-Abejón et al. 1998).

Neurotrophin-induced long-term synaptic plasticity (LTP) in the CA1 region of the hippocampus is severely compromised in BDNF knockout mice (Korte et al. 1995; Patterson et al. 1996). This deficit is, however, restored either by treatment with recombinant BDNF (Patterson et al. 1996) or following its expression in the hippocampal slices (Korte et al. 1996). Together, these studies demonstrate that various neurotrophic factors can indeed modulate the efficacy of synaptic transmission between both developing and mature synapses. However, their direct involvement in synapse formation is yet to be determined, because synaptogenesis between defined sets of pre- and postsynaptic neurons is often difficult to investigate directly in the vertebrate nervous system.

To seek a central analog for the peripheral NMJ, where the cellular and molecular mechanisms underlying synapse formation are better defined, synapses between the somata of invertebrate species have been developed. Central to this approach are synapses between the somata of identified leech (Fuchs et al. 1981, 1982; Nicholls et al. 1990), Helisoma (Haydon 1988), Aplysia (Klein 1994), and Lymnaea (Feng et al. 1997) neurons. In Lymnaea, the soma-soma synapses are both target cell contact specific and resemble (morphologically and electrophysiologically) those seen in vivo (Feng et al. 1997). Moreover, because these in vitro synapses form in the absence of neurite outgrowth, the involvement of trophic factors in synapse formation can be investigated directly.

Taking advantage of these unique features of the soma-soma synapse model, we have recently demonstrated that synapse formation between inhibitory partner cells right pedal dorsal 1 (RPeD1) and visceral dorsal 4 (VD4) is target cell-contact specific and requires de novo protein synthesis and transcription (Feng et al. 1997). These synapses did not, however, rely on the availability of any extrinsic trophic factors or substrate adhesion molecules. In the present study, however, we demonstrate that the excitatory synapses failed to develop in the absence of conditioned medium (CM). Specifically, we found that synapses between excitatory partner cells RPeD1 and visceral dorsal 2/3 (VD2/3) and between VD4 and left pedal dorsal 1 (LPeD1) failed to form in defined medium (DM). Instead, novel inappropriate inhibitory synapses developed between these cell pairs. We provide the first direct evidence that the substitution of DM with CM can correct inappropriate inhibitory synapses, in addition to promoting appropriate excitatory synapses. This trophic factor-induced plasticity of synaptic connections required de novo protein synthesis and was mediated via receptor tyrosine kinases.

\section{Materials and Methods}

ANIMALS

Laboratory-raised stocks of the fresh water snail Lymnaea stagnalis were maintained at room temperature and fed lettuce. For cell culture studies, $\sim 1$ - to 2-month-old (shell length 10-15 mm) animals were selected, whereas the brain CM was prepared from 2- to 3-month-old snails (shell length 15-25 mm).

\section{CELL CULTURE}

Neurons were isolated individually and cultured as described previously (Syed et al. 1990; Ridgway et al. 1991). Briefly, snails were anesthetized with 10\% Listerine (ethanol, $21.0 \%$; menthol, $0.042 \%)$ solution in normal saline $(51.3 \mathrm{~mm} \mathrm{NaCl}$,

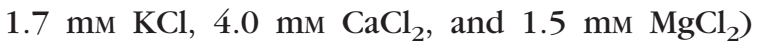
buffered to $\mathrm{pH} 7.9$ with HEPES. The central ring ganglia were isolated and subsequently disinfected in a series of antibiotic washes (gentamycin, 50 $\mu \mathrm{g} / \mathrm{ml}$; three washes, $15 \mathrm{~min}$ each). Following enzymatic treatment (for details, see Ridgway et al. 1991), the ganglia were pinned to the bottom of a dissection dish. Gentle suction was applied through a fire-polished and Sigmacote-treated pipette, and the somata were extracted individually. Isolated cells were plated onto poly-L-lysine-pretreated coverslips (Ridgway et al. 1991) in either DM (L-15; GIBCO BRL, Gaithersburg, MD; a special order) or CM. Neurons were juxtaposed in a soma-

$$
\begin{array}{lllllllllllllll}
L & E & A & R & N & I & N & G & \underset{308}{\boldsymbol{Q}} & M & E & M & O & R & Y
\end{array}
$$


soma configuration as reported previously (Feng et al. 1997). After 12-24 hr of cell pairing, the evidence for synaptic transmission between the neurons was obtained via simultaneous intracellular recordings.

\section{ELECTROPHYSIOLOGY}

Neuronal activity was monitored using conventional intracellular recording techniques (for details, see Syed and Winlow 1991). Specifically, glass microelectrodes (1.5-2.0 $\mu \mathrm{m}$ i.d.; World Precision Instruments) were filled with a saturated solution of $\mathrm{K}_{2} \mathrm{SO}_{4}$, yielding a tip resistance of 20-40 $\mathrm{M} \Omega$. Neurons were observed under an inverted microscope (Zeiss Axiovert 135) and impaled via Narashige (Tokyo, Japan) micromanipulators (MM202 and MM204). Electrical signals were amplified (NeuroData Instrument Corp.) and displayed on a digital storage oscilloscope (Philips, PM 3394) and recorded on a chart recorder (Gould, TA 240S).

\section{PREPARATION OF CM}

CM was prepared by incubating antibiotictreated ganglia in Sigmacote-pretreated glass petri dishes containing DM with added inorganic salts (40 mм NaCl, $1.7 \mathrm{~mm} \mathrm{KCl,} 4.1 \mathrm{~mm} \mathrm{CaCl}_{2}, 1.5 \mathrm{~mm}$ $\mathrm{MgCl}_{2}$, and $10 \mathrm{~mm} N^{\prime}-2$ hydroxyethyl-piperazine$N^{\prime}$-2-ethanesulfonic acid at $\left.\mathrm{pH} 7.9\right)$ and $20 \mu \mathrm{M}$ gentamycin. The petri dishes were then maintained in a humidified glass chamber (for details, see Wong et al. 1981). After 3 days, the incubated ganglia were removed, and the $\mathrm{CM}$ was frozen $\left(-20^{\circ} \mathrm{C}\right)$ until required.

\section{STATISTICS}

Fisher's Exact test (Sigma Stat; Jandel Scientific, San Rafael, CA) was used for data analysis.

\section{CHEMICALS}

With the exception of K252A (BIOMOL Research, EI-152) and KT5926 (BIOMOL Research, EI-201), all chemicals were obtained from Sigma.

\section{Results}

We have demonstrated previously that synapse formation between inhibitory synaptic partner cells RPeD1 and VD4 does not require trophic fac- tors derived from Lymnaea CM (Feng et al. 1997). To test whether synaptogenesis between excitatory partner cells could also occur in the absence of extrinsic trophic factors, two groups of presynaptic (RPeD1 and VD4) and postsynaptic (VD2/3 and LPeD1) neurons were paired in soma-soma configurations, either in the absence (DM only) or presence (CM) of trophic factors.

\section{INAPPROPRIATE INHIBITORY SYNAPSES DEVELOP IN DM}

Neurons were paired (RPeD1 and VD2/3, and VD4 and LPeD1) in soma-soma configurations in DM. After $12-24 \mathrm{hr}$, simultaneous intracellular recordings were made from both cell pairs. Intracellular injection of a depolarizing pulse into RPeD1 failed to produce excitatory postsynaptic responses in VD2/3 $(100 \% ; n=64)$ (Fig. 1A). Interestingly, however, an induced burst of spikes in VD2/3 inhibited the spontaneous spiking activity of RPeD1 (100\%; $n=64$ ) (Fig. 1B). Similarly, in DM, VD4 failed to establish its appropriate excitatory synapse with LPeD1; instead, inappropriate inhibitory synapses developed between these soma-soma paired cells. That is, an induced burst of action potentials in either VD4 (Fig. 1C) or LPeD1 (Fig. 1D) inhibited the firing of action potentials in the corresponding cell $(100 \% ; n=16)$. These inhibitory synapses were novel, as they do not exist either in the intact brain or in cell culture containing CM (Feng et al. 1997; T. Hamakawa, unpubl.). Taken together, these data demonstrate that in DM (1) excitatory synapses fail to develop, (2) novel inhibitory synapses form between VD2/3 and RPeD1 and between LPeD1 and VD4, and (3) all synapses formed were inhibitory.

\section{DM-INDUCED INAPPROPRIATE INHIBITORY SYNAPSES ARE CORRECTED BY CM}

We have shown previously that soma-soma pairing in CM results in appropriate excitatory synapse formation between all of the above pre- and postsynaptic cells (T. Hamakawa, unpubl.). In this study we asked whether substituting DM with CM after $12 \mathrm{hr}$ of soma-soma pairing could (1) still promote appropriate excitatory synapse formation between RPeD1 and VD2/3 and (2) correct the DM-induced inappropriate inhibitory synapses. To answer these questions, cells were paired in DM for an initial period of $12 \mathrm{hr}$. This was subsequently

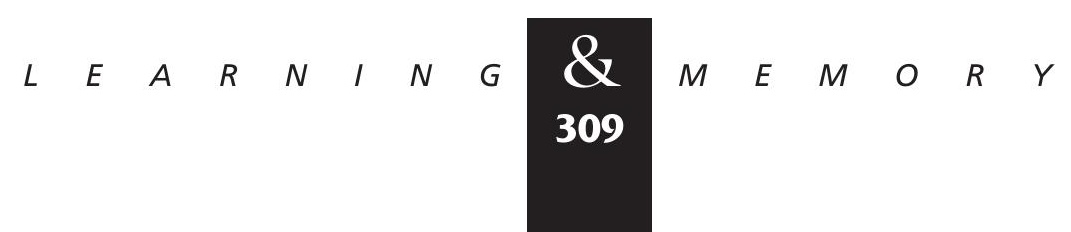




\section{Woodin et al.}

A

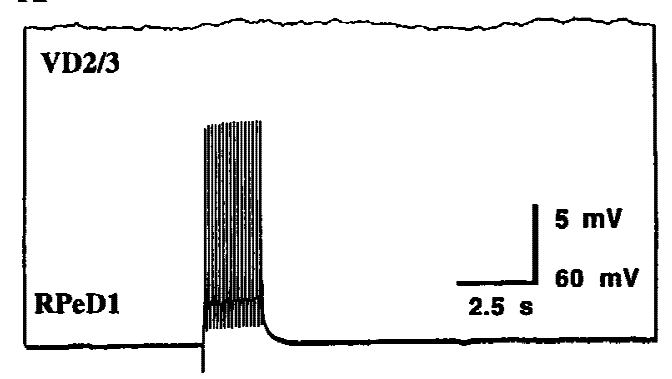

B

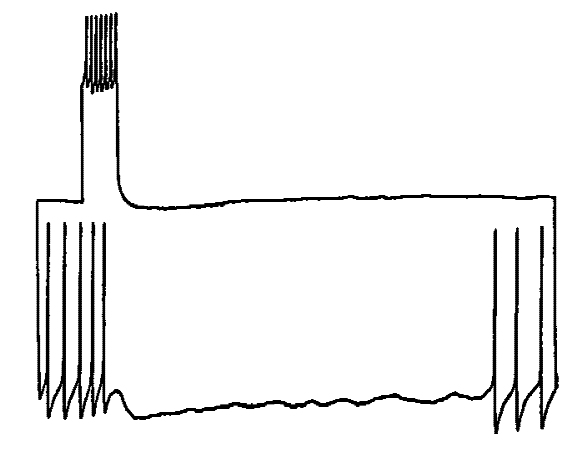

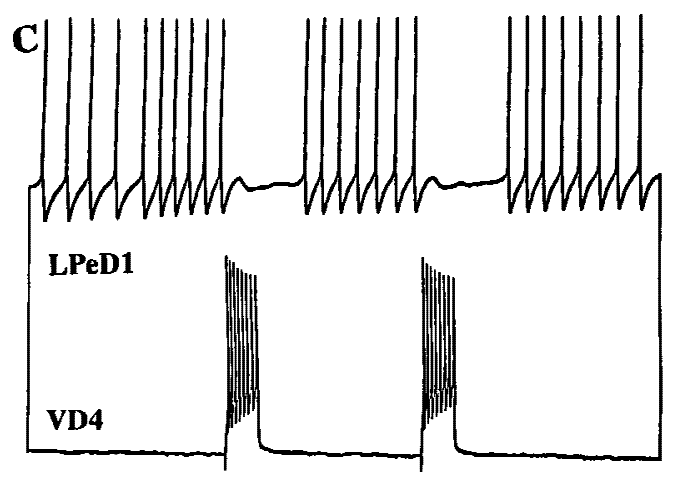

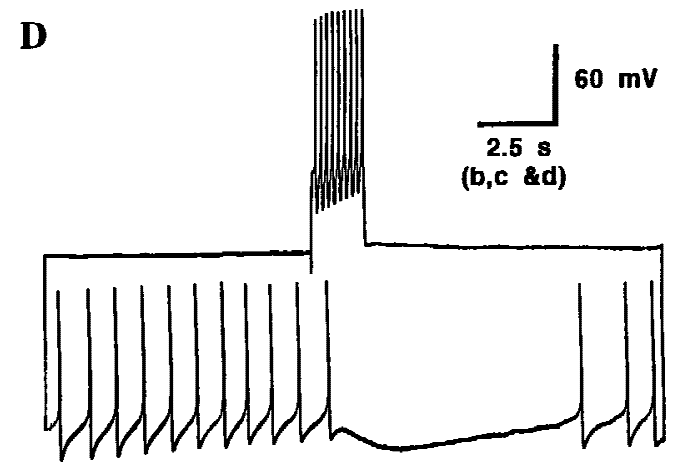

Figure 1: Inappropriate inhibitory synapses develop between soma-soma paired neurons in DM. After 12-24 hr of cell pairing in DM, simultaneous intracellular recordings revealed that a burst of action potentials in RPeD1 failed to alter the membrane potential of VD2/3 $(A)$, whereas compound action potentials in VD2/3 inhibited the firing of action potentials in RPeD1 $(B)$. Similarly, the spontaneous activity in VD4 was inhibited by an induced burst of action potentials in LPeD1 $(C)$, and vice versa $(D)$.

replaced with $\mathrm{CM}$, and neurons were maintained in this medium for an additional period of 6-12 hr. Simultaneous intracellular recordings revealed that action potentials in RPeD1 or VD4 produced excitatory postsynaptic potentials in VD2/3 (66\%; $n=21$ ) (Fig. 2B) and LPeD1 (80\%; $n=8)$ (Fig. 2D), respectively. This increase in excitatory synapse formation was statistically significant $(P<0.001)$. Additionally, we found that the incidence of inappropriate inhibitory synapse formation between VD2/3 and RPeD1 (34\%; $n=21$ ) (Fig. 2C) and also between LPeD1 and VD4 $(60 \% ; n=8)$ (Fig. 2E) decreased significantly $(P<0.001)$. A DM-to-DM substitution, on the other hand, did not promote excitatory synapse formation, nor were the inhibitory synapses eliminated. The above data (summarized in Fig. 3) provide direct evidence that CM not only promotes excitatory synapse formation but also reduces the incidence of inappropriate inhibitory synapse formation in DM.

It is possible that the CM-induced synaptic plasticity could have resulted from either a switch in the neurotransmitter phenotype of the presynaptic cell or the expression of a second "transmitter" (involved in the excitatory synaptic transmission). To reduce this possibility, we focused our studies on the RPeD1 and VD2/3 pair. RPeD1 has been shown to contain and release dopamine as its sole transmitter (Cottrell et al. 1979; McCaman et al. 1979; Magoski et al. 1995), and its synaptic transmission with VD2/3 is dopaminergic (Winlow and Benjamin 1977; Magoski et al. 1995).

\section{CM-INDUCED PLASTICITY OF EXCITATORY SYNAPTOGENESIS REQUIRES DE NOVO PROTEIN SYNTHESIS AND TRANSCRIPTION}

To ascertain whether the CM-induced plasticity of synaptic connections between RPeD1 and $\mathrm{VD} 2 / 3$ requires new protein synthesis and transcription, cells were incubated in CM containing either anisomycin $(12.5 \mu \mathrm{g} / \mathrm{ml})$ or actinomycin $\mathrm{D}$ $(1 \mu \mathrm{g} / \mathrm{ml})$, respectively. Neurons were first paired in $\mathrm{DM}$ for an initial period of $12 \mathrm{hr}$ (as described

$$
\begin{array}{lllllllllllllll}
L & E & A & R & N & I & N & G & \begin{array}{l}
\boldsymbol{Q} \\
\mathbf{3} 10
\end{array} & M & E & M & O & R & Y
\end{array}
$$




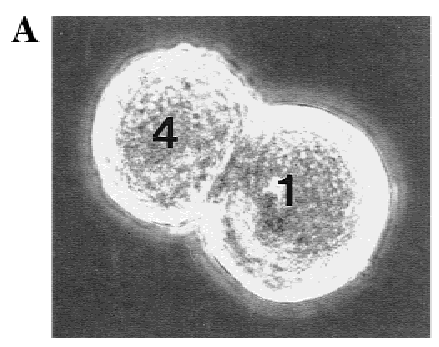

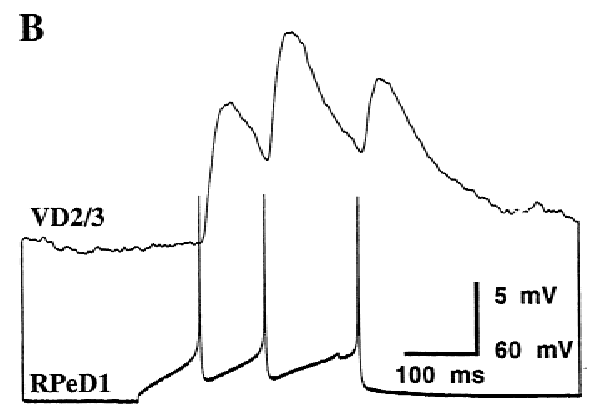

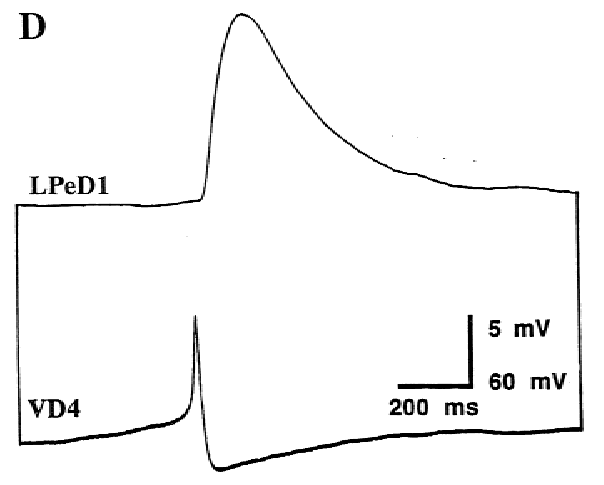

C

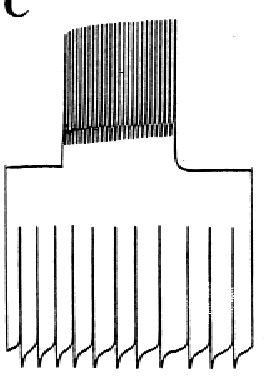

$\mathbf{E}$

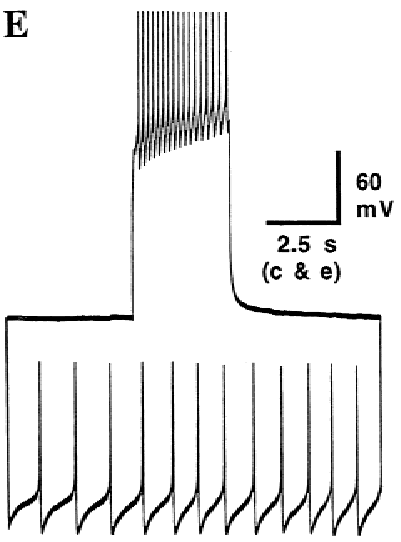

Figure 2: CM promotes excitatory synapse formation and reduces the incidence of DMinduced inappropriate inhibitory synaptic connections between identified Lymnaea neurons. Identified neurons were somasoma paired in DM for an initial period of 12 $\mathrm{hr}$, at which point DM was replaced with CM. (A) A photomicrograph of soma-soma paired neurons LPeD1 and VD4 in CM. Note that the paired cells do not extend neurites. Twelve to $24 \mathrm{hr}$ after CM substitution, simultaneous intracellular recordings revealed that the action potentials in RPeD1 produced 1:1 excitatory postsynaptic potentials (EPSPs) in VD2/3 (B), whereas a burst of action potentials in VD2/3 failed to alter the frequency of action potentials in RPeD1 $(C)$. Likewise, an action potential in VD4 produced a 1:1 EPSP in LPeD1 $(D)$. (E) Compound action potentials in LPeD1, however, failed to inhibit the firing of action potentials in VD4. above), and DM was subsequently replaced with CM containing either anisomycin or actinomycin. We discovered that cell pairs maintained in $\mathrm{CM}$ containing protein synthesis $(100 \% ; n=10)$ and transcription $(100 \% ; n=8)$ inhibitors failed to develop excitatory synapses (Fig. 4). Interestingly, these incubations also failed to "correct" the inappropriate inhibitory synapses. Taken together, these data show that CM-induced excitatory synapse formation and elimination of inappropriate inhibitory synapses are both contingent upon new protein synthesis and transcription.

\section{CM-INDUCED PLASTICITY OF EXCITATORY} SYNAPTOGENESIS IS MEDIATED BY RECEPTOR TYROSINE KINASES

Because most trophic factors, including Lym- naea $\mathrm{CM}$, are known to function via receptor tyrosine kinases, we sought to determine whether the CM-induced plasticity of synaptic connections between RPeD1 and VD2/3 also involved these receptors. RPeD1 and VD2/3 were soma-soma paired in DM, which was subsequently replaced with CM containing various inhibitors of the receptor tyrosine kinases. The $\mathrm{CM}$-induced effects on excitatory synapse formation were completely blocked by $10 \mu \mathrm{M}$ lavendustin A (100\%; $n=8)$, which is a specific receptor tyrosine kinase inhibitor; whereas its inactive analog lavendustin B (10 $\mu \mathrm{M})$ was ineffective $(0 \% ; n=9)$ (Fig. 5). Similarly, CM-induced plasticity of synaptogenesis was completely blocked by K252a (0.1 $\mu \mathrm{M})(100 \% ; n=8)$. Together, these data demonstrate that the CM-induced plasticity of synaptic connections is mediated by receptor tyrosine kinases.

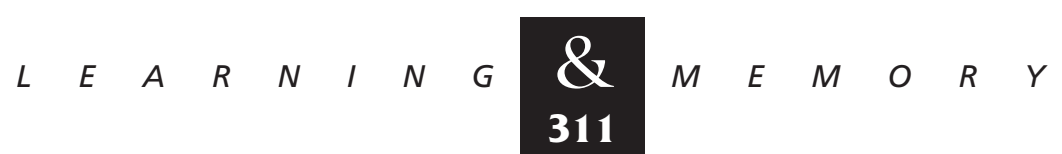




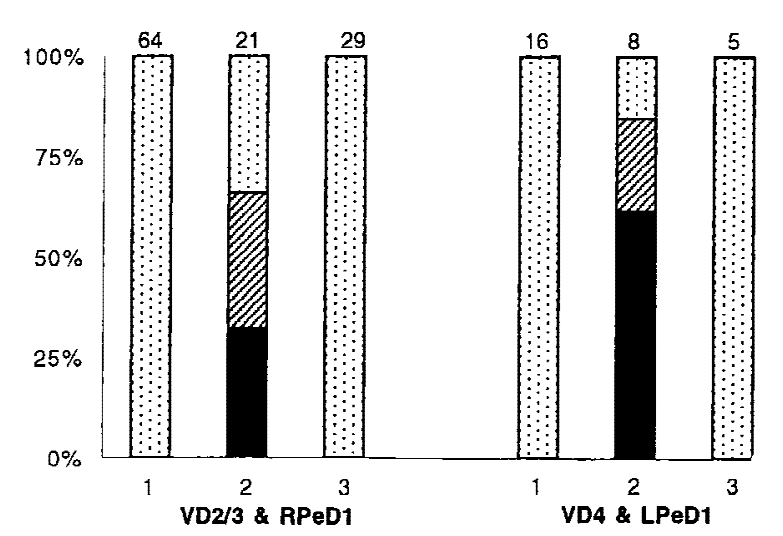

Figure 3: $C M$-induced plasticity of synaptic connections between identified Lymnaea neurons. Inappropriate inhibitory synapses developed in DM between RPeD1 and VD2/3, and VD4 and LPeD1 (1). Twelve hours after the initial soma-soma pairing, DM was replaced with CM (2), which in turn promoted the formation of excitatory synapses. When DM was replaced with DM, however, neither did the excitatory synapses develop nor were the inhibitory connections eliminated (3). (Solid bars) Excitatory synapses; (hatched bars) excitatory and inhibitory synapses; (dotted bars) inhibitory synapses. The $n$ values for each experiment are noted above the data bars.

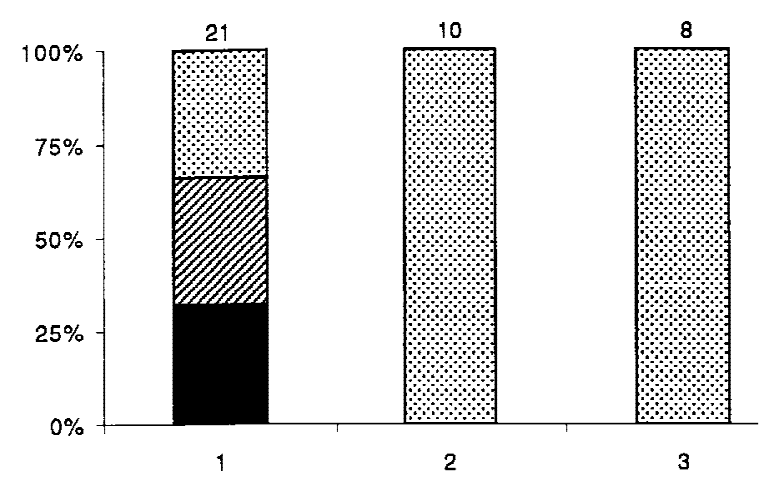

Figure 4: $\quad \mathrm{CM}$-induced plasticity of synaptic connections between RPeD1 and VD2/3 requires de novo protein synthesis and transcription. Twelve hours after the initial soma-soma pairing, DM was replaced with CM containing either a protein synthesis (anisomycin, 12.5 $\mu \mathrm{g} / \mathrm{ml}$ ) or a transcription (actinomycin D, $1 \mu \mathrm{M}$ ) blocker. (1) Twelve hours after initial soma-soma pairing, DM was replaced with CM. Inhibition of either protein synthesis (2) or transcription (3) blocked CM's ability to promote excitatory synapse formation. Inappropriate inhibitory synapses did however persist. (Solid bars) Excitatory synapses; (hatched bars) mixed excitatory and inhibitory synapses; (dotted bars) inhibitory synapses. The $n$ values for each experiment are noted above the data bars.

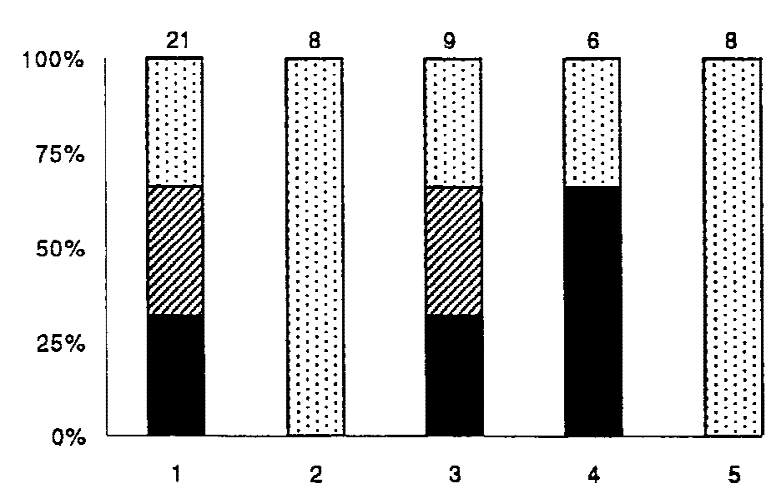

Figure 5: CM-induced plasticity of synaptic connections between identified Lymnaea neurons is mediated via receptor tyrosine kinases. RPeD1 and VD2/3 were soma-soma paired in DM for $12 \mathrm{hr}$. DM was subsequently replaced with CM containing a receptor tyrosine kinase inhibitor. (1)Twelve hours after initial soma-soma pairing, DM was replaced with CM. The CM-induced synaptic plasticity was either blocked completely or reduced significantly in the presence of $\mathrm{CM}$ containing a receptor tyrosine kinase inhibitor [(2) Lavendustin A, 10 $\mu \mathrm{M} ;$ (5) K252a, $0.1 \mu \mathrm{M}$ ]. CM containing the inactive forms of receptor tyrosine kinase inhibitors [(3) Lavendustin $B, 10 \mu \mathrm{M}$ ] were, however, ineffective in perturbing the CM-induced excitatory synapse formation. Similarly, the addition of DMSO [(4) carrier solution, 1\%] failed to affect $\mathrm{CM}$-induced plasticity of synaptic connections between RPeD1 and VD2/3 pairs. The $n$ values for each experiment are noted above the data bars.

\section{Discussion}

This study demonstrated that trophic factors are required for excitatory but not inhibitory synaptogenesis between soma-soma paired Lymnaea neurons. Moreover, we showed that in the absence of trophic factors, not only did neurons fail to establish appropriate excitatory synapses but also that inappropriate inhibitory synapses developed in a soma-soma configuration. We designate these synapses as novel and inappropriate because they do not exist in the intact nervous system and are rare between identified Lymnaea neurons in cell culture (Bulloch and Syed 1992). Novel inappropriate synapses have, however, been observed between cultured neurons from many other invertebrate species. For example, in the intact ganglion preparation, Aplysia neurons R15 and R16 receive excitatory inputs from L10; however, when cultured in the presence of hemolymph, novel inhibitory synaptic connections develop between L10 and its postsynaptic partners (Kleinfeld et al. 1990). Furthermore, novel inhibitory synapses also

$$
\begin{array}{lllllllllllllll}
\hline & E & A & R & N & I & N & G & \begin{array}{l}
\boldsymbol{Q} \\
\mathbf{3 1 2}
\end{array} & M & E & M & O & R & Y
\end{array}
$$


develop between identified leech neurons cultured in serum (Arechiga et al. 1986). It is interesting to note that in most instances these novel synapses were inhibitory in nature. Because novel inhibitory synapses between both Aplysia and leech neurons occurred in hemolymph and serum, respectively, it is likely that these sources of trophic support might not contain specific molecules necessary for excitatory synapse formation. Because both Aplysia hemolymph and leech serum did nevertheless promote neurite outgrowth from their respective neurons, these studies suggest that the trophic factors mediating neurite outgrowth and synapse formation are most likely different.

Taken together with our data, the above studies reveal a general trend; in the absence of appropriate trophic factors, neurons establish novel inappropriate inhibitory synapses. These synapses were considered novel because neither do they exist in vivo nor are they observed in vitro when cells are cultured in the presence of CM. It is im- portant to realize that in our hands, Lymnaea neurons do not exhibit either transient electrical coupling or chemical inhibitory synapses prior to excitatory synaptogenesis (M.A. Woodin, K. Lukowiak, and N.I. Syed, unpubl.). Because inhibitory synapses (which require strong depolarizing input; see Fig. 3) are likely to be less detrimental to the developing nervous system than their excitatory counterparts, we propose that these are most likely "default synapses" (Fig. 6). It is important to note that the CM-induced "correction" of synapses seen in the present study involved only inappropriate inhibitory synaptic connections, whereas appropriate inhibitory synaptic connections between RPeD1 and VD4 do not change from DM to CM (Feng et al. 1997). On the basis of our observations in the Lymnaea model, we predict that, should transient synapses form during development, these would fall into a "default" category.

Consistent with the above idea are data from other laboratories, which show that both excit-

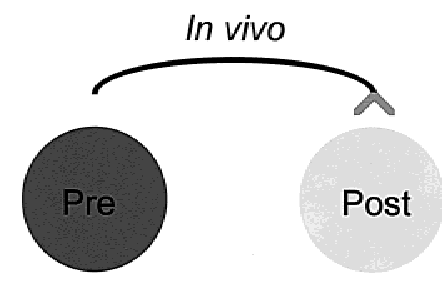

In vitro

(+) Trophic Factors

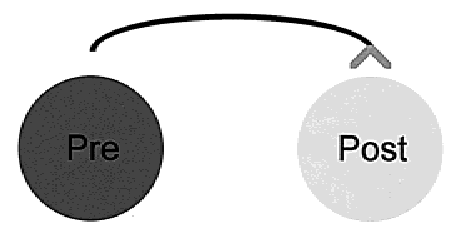

In vitro

(-) Trophic Factors

"Default" synapses

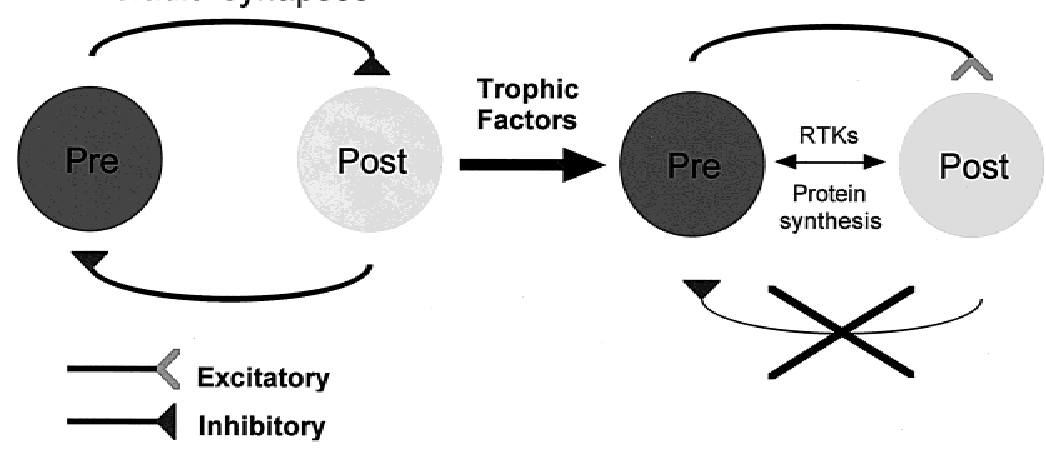

Figure 6: A model depicting the CM-induced plasticity of synapse formation between soma-soma paired Lymnaea neurons. In the presence of trophic factors [(+) trophic factors] identified Lymnaea neurons form appropriate excitatory synapses. In the absence of trophic factors [(-) trophic factors], however, inappropriate inhibitory synapses develop in vitro. Because these synapses are novel and inhibitory, we have termed them default synapses. These inappropriate inhibitory synapses are reduced in incidence by the addition of CM-derived trophic molecules (thick black arrow), which also induce appropriate excitatory synapse formation between the paired cells. This trophic factor-induced plasticity requires de novo protein synthesis and is mediated via receptor tyrosine kinases (RTKs).

$$
\begin{array}{lllllllllllllll}
L & E & A & R & N & I & N & G & \begin{array}{l}
\boldsymbol{Q} \\
\mathbf{3} 13
\end{array} & M & E & M & O & R & Y
\end{array}
$$


atory synapse formation and inhibitory synapse formation between mammalian neurons are also differentially regulated by trophic factors. For example BDNF promotes excitatory and inhibitory synapse formation, whereas NT-3 induces the formation of excitatory synapses only (Vicario-Abéjon 1998). In Lymnaea, we have shown previously that both neurite outgrowth and synapse formation are differentially regulated by vertebrate nerve growth factor (NGF) and ciliary neurotrophic factor (CNTF) (Syed et al. 1996). Specifically, although both NGF and CNTF promoted neurite outgrowth from a select group of identified Lymnaea neurons, the CNTF-induced neurite outgrowth did not, however, result in synapse formation. Again, an important insight to be gained from these studies is that the growth factors, that promote neurite outgrowth may not be sufficient to induce specific synapse formation between neurons.

Interestingly, the DM-induced inappropriate inhibitory synapses were qualitatively different from the excitatory synapses that had formed in CM. In almost all instances of novel inhibitory synapses, a burst of action potentials was often required to produce a compound, postsynaptic inhibitory response in the corresponding cell. Even in those instances in which the postsynaptic cell was hyperpolarized to prevent spiking activity, presynaptic action potentials were unable to produce unitary PSPs (data not shown). In CM, on the other hand, single action potentials were always found sufficient to produce 1:1 EPSPs in the postsynaptic cell (Fig. 2B,D). These data suggest that the DM-induced inhibitory synapses are "immature" and that their synaptic machinery may not be fully developed.

Although the precise identity of CM-derived trophic factors has not yet been fully deduced, a number of potential candidate molecules have been identified. For instance, in Lymnaea a cysteine-rich neurotrophic factor (CRNF) has been identified that binds to the mammalian p75 receptor and promotes neurite outgrowth from a select group of identified neurons (Fainzilber et al. 1996). Similarly, epidermal growth factor (EGF) purified from Lymnaea albumen gland mimics the CM-induced effects on both neurite outgrowth (P.M. Hermann, W.C. Wildering, S.D. Painter, G.T. Nagle, and A.G.M. Bulloch, unpubl.) and excitatory synapse formation (T. Hamakawa, unpubl.). More recently, we have isolated a potential candidate molecule from Lymnaea CM, which mimics CMinduced effects on the excitatory synapse forma- tion between soma-soma paired neurons (M.A. Woodin, unpubl.). Further identification and characterization of this trophic molecule will enable us to examine the cellular and molecular mechanisms underlying CM-induced plasticity of synaptic connections between soma-soma paired cells.

Neurotrophin-induced effects on synaptic plasticity involve receptor tyrosine kinases (Thoenen 1995; McAllister et al. 1999). These changes are either short term, involving a mere modification of the pre-existing proteins, or long term, requiring new protein synthesis (Goelet et al. 1986; Bailey et al. 1996). The present study demonstrated that the CM-induced synaptic plasticity required de novo protein synthesis and transcription, suggesting that the trophic factor-induced plasticity of synaptic connections involves long-term alterations either in synaptic structure or function, independent of new neurite outgrowth (T. Hamakawa, unpubl.). Moreover, because CM-induced effects on the plasticity of synaptic connections between soma-soma paired cells were blocked by receptor tyrosine kinase inhibitors, these data further confirm the involvement of CM-derived trophic factors in synapse formation between Lymnaea neurons.

A number of pre- and postsynaptic mechanisms can account for the CM-induced plasticity of synaptic connections (for review, see McAllister et al. 1999). For instance, as observed in other systems, trophic molecules present in CM may either alter the expression of presynaptic transmitter phenotype in RPeD1 or modulate transmitter release. For example, extracellular application of BDNF has been shown to elevate presynaptic cytosolic $\mathrm{Ca}^{2+}$ levels, which in turn increase the probability of transmitter release (Berninger et al. 1993; Stoop and Poo 1996; Li et al. 1998). Similarly, neurotrophins can also modulate postsynaptic mechanisms in VD4 by altering either the expression of various ion channels or postsynaptic dopamine receptors. In addition, the trophic factors may also stimulate activity-dependent mechanisms that would be required for excitatory but not inhibitory synapse formation and plasticity.

Our data, in conjunction with previously published studies (Feng et al. 1997, T. Hamakawa, unpubl.), lead us to propose the following model for neurotrophic factor-induced plasticity of synaptic connections in the nervous system (Fig. 6):

1. The trophic factors that mediate neurite outgrowth and synapse formation are probably distinct.

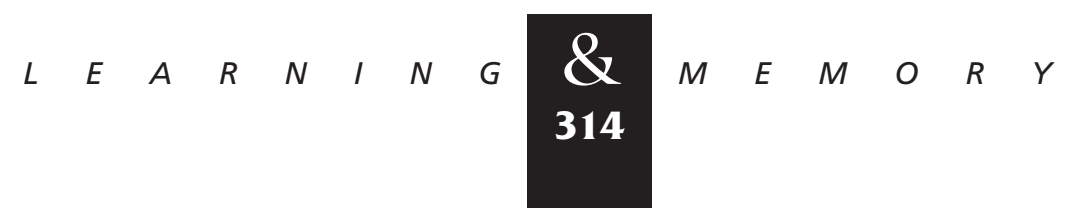


2. Given the choice of the correct target cell, neurons establish appropriate inhibitory synapses in the absence of extrinsic trophic factors.

3. Target cell contact alone is insufficient for excitatory synapse formation, which requires extrinsic trophic factors.

4. Trophic factor-induced synapse formation requires new protein synthesis and transcription and is mediated via receptor tyrosine kinases.

5. In the absence of trophic support, inappropriate inhibitory synapses develop between excitatory partners, which can however be corrected by the addition of trophic factors.

6. The presence of trophic factors at the time of cell-cell pairing is not essential, because synapses can either be induced or eliminated at a later time point.

\section{Acknowledgments}

This work was supported by the Medical Research Council of Canada (MRC). N.I.S. is an Alberta Heritage Foundation for Medical Research (AHFMR) Senior Scholar; M.W. was supported by studentship awards from the AHFMR and MRC. Excellent technical support by Wali Zaidi is also acknowledged.

The publication costs of this article were defrayed in part by payment of page charges. This article must therefore be hereby marked "advertisement" in accordance with 18 USC section 1734 solely to indicate this fact.

\section{References}

Arechiga, H., M. Chiquet, D.P. Kuffler, and J.G. Nicholls. 1986. Formation of specific connections in culture by identified leech neurones containing serotonin, acetylcholine and peptide transmitters. J. Exp. Biol. 126: 15-31.

Bailey, C.H., D. Bartsch, and E.R. Kandel. 1996. Toward a molecular definition of long-term memory storage. Proc. Natl. Acad. Sci. 93: 13445-13452.

Berninger, B., D.E. Garcia, N. Inagaki, C. Hahnel, and D. Lindholm. 1993. BDNF and NT-3 induced intracellular $\mathrm{Ca}^{2+}$ elevation in hippocampal neurons. NeuroReport 4: 1303-1306.

Bulloch, A.G.M. and N.I. Syed. 1992. Reconstruction of neuronal networks in culture. Trends Neurosci. 15: 422-427.

Cottrell, G.A., B.K. Abernethy, and M.A. Barrand. 1979. Large amine-containing neurones in the central ganglia of Lymnaea stagnalis. Neuroscience 4: 685-689.

Fainzilber, M., A.B. Smit, N.I. Syed, W.C. Wildering, P.M. Hermann, R.C. van der Schors, C. Jiménez, K.W. Li, J. van Minnen, A.G.M. Bulloch, C.F. Ibáñez, and W.P.M. Geraerts. 1996. CRNF, a molluscan neurotrophic factor that interacts with the p75 neurotrophin receptor. Science 274: 1540-1543.
Feng, Z-P., J. Klumperman, K. Lukowiak, and N.I. Syed. 1997. In vitro synaptogenesis between the somata of identified Lymnaea neurons requires protein synthesis but not extrinsic growth factors or substrate adhesion molecules. J. Neurosci. 17: 7839-7849.

Fuchs, P.A., J.G. Nicholls, and D.F. Ready. 1981. Membrane properties and selective connections of identified leech neurons in culture. J. Physiol. (Lond.) 316: 203-223.

Fuchs, P.A., L.P. Henderson, and J.G. Nicholls. 1982. Chemical transmission between individual Ritzius cells and sensory neurons of leech in culture. J. Physiol. (Lond.) 323: 195-210.

Goelet, P., V.F. Castellucci, S. Schacher, and E.R. Kandel. 1986. The long and the short of long-term memory-A molecular framework. Nature 322: 419-422.

Haydon, P.G. 1988. The formation of chemical synapses between cell-cultured neuronal somata. J. Neurosci. 8: 1032-1038.

Kang, H. and E.M. Schuman. 1995. Long-lasting neurotrophin-induced enhancement of synaptic transmission in the adult hippocampus. Science 267: 1658-1662.

Kim, H.G., T. Wang, P. Olafsson, and B. Lu. 1994. Neurotrophin-3 potentiates neuronal activity and inhibits G-aminobutyratergic synaptic transmission in cortical neurons. Proc. Natl. Acad. Sci. 91: 12341-12345.

Klein, M. 1994. Synaptic augmentation by 5-HT at rested Aplysia sensorimotor synapses: Independence of action potential prolongation. Neuron 13: 159-166.

Kleinfeld, D., T.D. Parsons, F. Raccuia-Behling, B.M. Salzberg, and A.L. Obaid. 1990. Foreign connections are formed in vitro by Aplysia californica interneurone L10 and its in vivo followers and non-followers. J. Exp. Biol. 154: 237-255.

Korte, M., P. Carroll, E. Wolf, G. Brem, H. Thoenen, and T. Bonhoeffer. 1995. Hippocampal long-term potentiation is impaired in mice lacking brain-derived neurotrophic factor. Proc. Natl. Acad. Sci. 92: 8856-8860.

Korte, M., O. Griesbeck, C. Gravel, P. Carroll, V. Staiger, $\mathrm{H}$. Thoenen, and T. Bonhoeffer. 1996. Virus-mediated gene transfer into hippocampal CA1 region restores long-term potentiation in brain-derived neurotrophic factor mutant mice. Proc. Natl. Acad. Sci. 93: 12547-12552.

Lessmann, V., K. Gottmann, and R. Heumann. 1994. BDNF and NT-4/5 enhance glutamatergic synaptic transmission in cultured hippocampal neurones. NeuroReport 6: 21-25.

Levine, E.S., C.F. Dreyfus, I.B. Black, and M.R. Plummer. 1995. Brain-derived neurotrophic factor rapidly enhances synaptic transmission in hippocampal neurons via postsynaptic tyrosine kinase receptors. Proc. Natl. Acad. Sci. 92: 8074-8077.

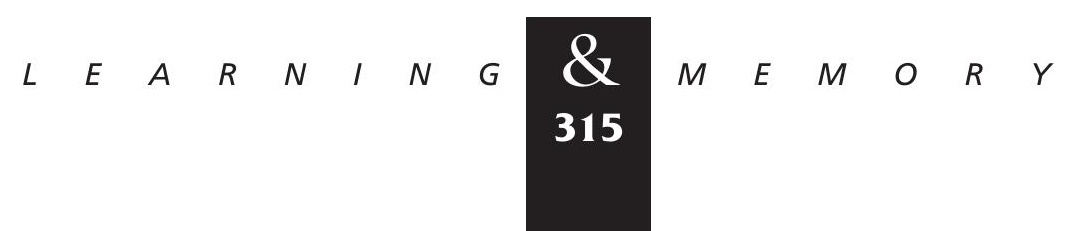




\section{Woodin et al.}

Li, Y.X., Y. Zhang, H.A. Lester, E.M. Schuman, and N. Davidson. 1998. Enhancement of neurotransmitter release induced by brain-derived neurotrophic factor in cultured hippocampal neurons. J. Neurosci. 18:(24) 10231-10240.

Liou, J.C., R.S. Yang, and W.M. Fu. 1997. Regulation of quantal secretion by neurotrophic factors at developing motoneurons in Xenopus cell cultures. J. Physiol. (Lond.) 503: 129-139.

Lohof, A.M., M.Y. Ip, and M-M. Poo. 1993. Potentiation of developing neuromuscular synapses by the neurotrophins NT-3 and BDNF. Nature 363: 350-353.

Magoski, N.S., L.G. Bauce, N.I. Syed, and A.G.M. Bulloch. 1995. Dopaminergic transmission between identified neurons from the mollusc Lymnaea stagnalis. J. Neurophysiol. 74: 1287-1300.

McAllister, A.K., L.C. Katz, and D.C. Lo. 1999.

Neurotrophins and synaptic plasticity. Annu. Rev. Neurosci. 22: 295-318.

McCaman, M.W., J.K. Ono, and R.E. McCaman. 1979. Dopamine measurements in molluscan ganglia and neurons using a new, sensitive assay. J. Neurochem. 32: 1111-1113.

Nicholls, J.G., Y. Liu, B.W. Payton, and D.P. Kuffler. 1990. The specificity of synapse formation by identified leech neurones in culture. J. Exp. Biol. 153: 141-154.

Patterson, S.L., T. Abel, T.A.S. Deuel, K.C. Martin, J.C. Rose, and E.R. Kandel. 1996. Recombinant BDNF rescues deficits in basal synaptic transmission and hippocampal LTP in BDNF knockout mice. Neuron 16: 1137-1145.

Ridgway, R.L., N.I. Syed, K. Lukowiak, and A.G.M. Bulloch. 1991. Nerve growth factor (NGF) induces sprouting of specific neurons of the snail, Lymnaea stagnalis. J. Neurobiol. 22: $377-390$.

Schuman, E.M. 1997. Synapse specificity and long-term information storage. Neuron 18: 339-342.

Stoop, R. and M.-M. Poo. 1996. Synaptic modulation by neurotrophic factors: Differential and synergistic effects of brain-derived neurotrophic factor and ciliary neurotrophic factor. J. Neurosci. 16:(10) 3256-3264.

Syed, N.I. and W. Winlow. 1991. Respiratory behaviour in the pond snail Lymnaea stagnalis. II. Neural elements of the central pattern generator (CPG). J. Comp. Physiol.

169: $557-568$.

Syed, N.I., A.G.M. Bulloch, and K. Lukowiak. 1990. In vitro reconstruction of the respiratory central pattern generator of the mollusk Lymnaea. Science 250: 282-285.

Syed, N., P. Richardson, and A.G.M. Bulloch. 1996. Ciliary neurotrophic factor unlike nerve growth factor supports neurite outgrowth but not synapse formation by adult Lymnaea neurons. J. Neurobiol. 29: 293-303.
Tanaka, T., H. Saito, and N. Matsuki. 1997. Inhibition of $\mathrm{GABA}_{\mathrm{A}}$ synaptic responses by brain-derived neurotrophic factor (BDNF) in rat hippocampus. J. Neurosci. 17: 2959-2966.

Thoenen, H. 1995. Neurotrophins and neuronal plasticity. Science 270: 593-598.

Vicario-Abejón, C., C. Collin, R.D.G. McKay, and M. Segal. 1998. Neurotrophins induce formation of functional excitatory and inhibitory synapses between cultured hippocampal neurons. J. Neurosci. 18: 7256-7271.

Wang, T., K. Xie, and B. Lu. 1995. Neurotrophins promote maturation of developing neuromuscular synapses. J. Neurosci. 15: 4796-4805.

Winlow, W. and P.R. Benjamin. 1977. Postsynaptic effects of a multiaction giant interneurone on identified snail neurones. Nature 268: 263-265.

Wong, R.G., R.D. Hadley, S.B. Kater, and G.C. Hauser. 1981. Neurite outgrowth in molluscan organ and cell cultures: The role of conditioning factor(s). J. Neurosci. 1: 1008-1021.

Received May 19, 1999; accepted in revised form July 7, 1999.

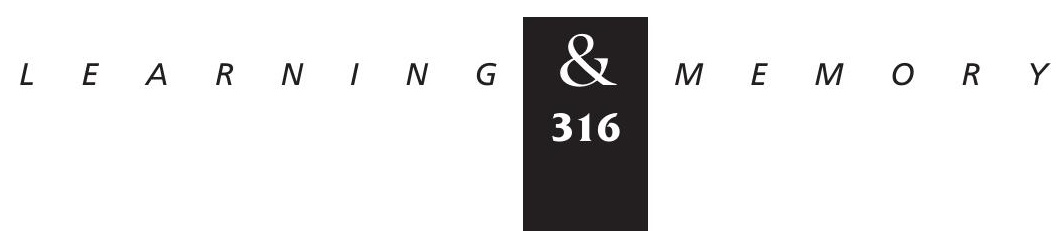




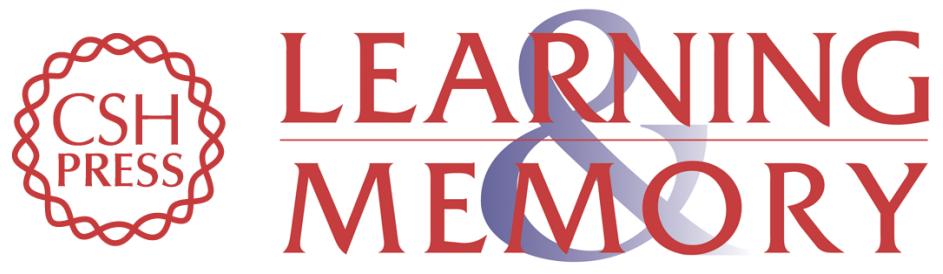

\section{Trophic Factor-Induced Plasticity of Synaptic Connections Between Identified Lymnaea Neurons}

Melanie A. Woodin, Toshiro Hamakawa, Mayumi Takasaki, et al.

Learn. Mem. 1999, 6:

Access the most recent version at doi:10.1101//m.6.3.307

References This article cites 39 articles, 20 of which can be accessed free at: http://learnmem.cshlp.org/content/6/3/307.full.html\#ref-list-1

License

Email Alerting Receive free email alerts when new articles cite this article - sign up in the box at the Service top right corner of the article or click here. 